BLS 35, No 1 2009. DOI: http://dx.doi.org/10.3765/bls.v35i1.3615

(published by the Berkeley Linguistics Society and the Linguistic Society of America)

\title{
Verb Serialization and Argument Unification? A Case Study of Three Serial Verb Constructions in Tsou
}

\author{
GUJING LIN \\ Rice University
}

\section{Introduction}

Serial verb constructions are a long-standing problem for most syntactic theories, which assume that verbs are unique within their clauses. Contrary to this assumption, a serial verb construction is often portrayed as a construction in which two or more verbs act together (as a single predicate) in a monoclausal structure, with only one specification for tense, aspect, modality, and negation (cf. Foley and Olson 1985, Bisang 1995, Durie 1997, Crowley 2002, Bril 2004, to name a few).

The present paper analyzes three serial verb constructions (henceforth SVCs) in Tsou. Using evidence from focus-marking and nominal morphology, I argue that arguments of individual verbs in the Tsou SVCs are not fused into a fully unified argument structure governed by the entire verb series, although the individual verbs are encompassed in a monoclausal structure sharing one specification of mood, person, and polarity values.

In what follows, I discuss the morphosyntactic properties of these Tsou SVCs focusing on their implications to the configuration of argument structure in this Austronesian language. I will contrast the features of Tsou SVCs with the two properties of SVCs that linguists most often talk about: (i) that serial verbs do not display any sort of syntactic dependency, and (ii) that verb serialization involves argument fusion.

\section{Literature on Verb Serialization}

A commonly cited SVC definition is that of Aikhenvald (2006:1), who claims that:

A serial verb construction is a sequence of verbs which act together as a single predicate, without any overt marker of coordination, subordination, or syntactic dependency of any other sort. Serial verbs describe what can be conceptualized as a single event. They are monoclausal; their intonational properties are those of a monoverbal clause, and they have just one tense, aspect, and polarity value. Serial verbs may also share arguments and obliques. Each component of an SVC must be able to occur on its own. 


\section{Gujing Lin}

In Aikhenvald's definition, the lack of syntactic dependency is the defining criterion that distinguishes SVCs from other types of complex predicates and from multi-verb constructions like coordination and subordination. Bril lists similar criteria, arguing that 'lexical autonomy is a prerequisite for serialization, excluding non-autonomous coverbs and nonfinite forms, as well as co-lexicalized compounds' (Bril 2004:3). Each of the serialized verbs is assumed to manifest the full-fledged finiteness and to be able to occur as the main predicate in an independent sentence. Bisang (1995) compares SVCs with converb constructions and points to lexical autonomy as the substantive difference that keep the two constructions distinct. According to Bisang, verb serialization is the unmarked juxtaposition of two or more verbs, each of which would also be able to form a sentence on its own (Bisang 1995:139). Converbs, on the contrary, are verb forms that cannot occur as main predicates of independent sentences.

The claim that SVCs involve the juxtaposition of fully autonomous verbs which together constitute a single predication presents a clear challenge to many syntactic theories, most of which assume that verbs are unique within their clauses and predicatehood is therefore equivalent to clausehood. Such an equation becomes problematic when SVCs are taken into consideration. The immediate problem is: how should predicatehood be gauged in SVCs? On the one hand, SVCs are said to act together as a single predicate. On the other, each of the serialized verbs is said to be able to occur on its own and make its own predication. Shibatani (2007:12) points to us that the common understanding of SVCs in fact involves a contradiction: if serial verbs together form a single predication, how could they each function as finite forms and make predication separately?

Regarding the contradiction, Shibatani argues that "if serial verbs constitute one single predication, as in Bril's characterization, the individual verbs shouldn't be able to function autonomously because they do not make predication separately" (2007:12). That is, although serial verbs are often depicted as the juxtaposition of two syntactically autonomous verbs, only one verb in the series is fully autonomous/finite; other verbs are restricted in functions and are not fully finite. The syntactic dependence between serial verbs, according to Shibatani, has been illustrated languages such as Paamese, based on Crowley's description. Crowley (2002) pointed out that the second verb in the Paamese SVC in (1) below is severly restricted; it is devoid of clitic and mood marking (although it may still display a number of finiteness features), unlike the independent verb in the second clause in (2). In Paamese SVCs, only the first verb has the potential of displaying the full range of formal finiteness features. ${ }^{1}$ In a word, lack of overt dependency marking is no evidence that individual verbs in SVCs are necessarily fully autonomous and finite.

\footnotetext{
${ }^{1}$ Abbreviations used in the present paper include: SG: singular; PL: plural; R/REAL: realis; AUX: auxiliary; AF: ACTOR-FOCUS; PF: PATIENT-FOCUS; RF: REFERENCE-FOCUS; LF: LOCATION-FOCUS; NAF: NON-ACTOR-FOCUS; TOP: TOPIC; NTOP: NON-TOPIC.
} 
Paamese SVCs (Crowley 1987:43)

$$
\begin{aligned}
& \text { kail a-muas vuas emat } \\
& \text { 3PL 3PL.REAL-hit pig 3SG.REAL-die } \\
& \text { 'They killed the pig by hitting it.' }
\end{aligned}
$$

$$
\begin{aligned}
& \text { kail a-muas vuas kai emat } \\
& \text { 3PL 3PL.REAL-hit pig 3SG 3SG.REAL-die } \\
& \text { 'They hit the pig and it died.' }
\end{aligned}
$$

If SVCs are not formed of equally autonomous verbs, we need to rethink their implications to the configuration of argument structure: Are finite verbs and dependent verbs equally important in determining the argument structure licensed by the newly-formed joint predicate? That is, does the serial complex together subcategorize all the arguments contributed by each of its component verbs? Aikhenvald's characterization states that serial verbs may share arguments and obliques; there is no mention whether or not arguments of individual verbs are fully unified, even though by claiming serial verb acting together as a single predicate, a single unified argument structure is implicated. Unlike Aikhenvald, Durie (1997:340-349) explicitly argues that arguments of individual verbs are integrated into a fused argument structure, but the fused structure may involve a new conceptual structure and assign different semantic attributes to the arguments involved.

\section{A Sketch of Tsou Clause Structure}

Tsou is an Austronesian language currently spoken in southwestern Taiwan. Most Tsou clauses begin with an auxiliary and a predicate, with nominals following immediately behind. Every nominal is preceded by a particle indicating the dependency relation of the nominal to its licensing predicate. The pre-nominal particle illustrates a two-way contrast, referred to as the TOPIC vs. NON-TOPIC distinction in the present study. A clause may contain multiple nominals coded as the NON-TOPIC, but only one nominal can be selected for the TOPIC, as shown in the examples (3)-(6) below.

$$
\begin{array}{llllll}
\text { mo }=\varnothing & \text { mo-si } & \text { to } & \text { ca'hU to pooyoyo } & \text { 'o amo } \\
\text { AUX.AF.R=3SG } & \text { AF-put } & \text { NTOP } & \text { table } & \text { NTOP pants } & \text { TOP father }
\end{array}
$$

'Father put pants on a/the chair.' (agent=TOP, AF verb, AF aux)

$$
\begin{aligned}
& \mathrm{i}=\mathrm{si} \quad \text { si-a to ca'hU to amo 'o pooyoyo } \\
& \text { AUX.NAF.R=3SG put-PF NTOP table NTOP father TOP pants } \\
& \text { 'Father put the pants on a/the chair.' (patient=TOP, PF verb, NAF aux) }
\end{aligned}
$$




\section{Gujing Lin}

$$
\text { i=si si-eni to pooyoyo to amo 'o oko }
$$

AUX.NAF.R $=3$ SG put-RF NTOP pants NTOP father TOP child 'Father put aside pants for the child.' (ben= TOP, RF verb, NAF aux)

$$
\begin{array}{llllll}
\mathrm{i}=\mathrm{si} & \text { si-i to } & \text { pooyoyo to amo 'o ca'hU } \\
\text { AUX.NAF.R=3SG put-LF NTOP pants NTOP father } & \text { TOP chair } \\
\text { 'Father put pants on the chair.' (location=TOP, LF verb, NAF aux) }
\end{array}
$$

The verbal marking system in Tsou displays the Philippine-type voice/focus conrast. Depending on the nominal that bears the TOPIC marking, a verb may appear in at most four different focus forms: ACTOR FOCUS, PATIENT FOCUS, REFERENCE FOCUS, and LOCATION FOCUS. The examples in (3)-(6) illustrate the four focus forms of the lexical root si 'put': mo-si (AF), si-a (PF), si-eni (RF), and si- $i$ (LF). The three NON-ACTOR-FOCUS forms are conventionally referred to as NAF forms collectively.

Verbs are not the only place where focus marking is indicated. A characteristic feature of Tsou is that focus marking is simultaneously registered on the co-occurring auxiliary in realis mood. An AF verb requires an AF auxiliary, but verbs marked in the other three focus forms take a NAF auxiliary instead, as shown in (7) and (8) below. Aside from focus and mood, the Tsou auxiliary also attracts prominal marking, which invariably coreferences the actor of the clause, as shown in the first person singular marking $=' o$ in (7) and (8).

$$
\begin{aligned}
& \text { mi='o } \quad c<m>\text { uhu to moatU'nU } \\
& \text { AUX.AF.R=1SG }<\text { AF>butcher TOP goat } \\
& \text { 'I butchered a goat.' (AF aux, agent=TOP) }
\end{aligned}
$$

$$
\begin{array}{llll}
\text { i='o } & \text { chu-a } & \text { 'o } & \text { moatU'nU } \\
\text { AUX.AF.R=1SG butcher-PF } & \text { TOP } & \text { goat } \\
\text { 'I butchered the goat.' (NAF aux, patient=TOP) }
\end{array}
$$

The four-way contrast as shown in (3)-(6) raises a question regarding the common understanding of argument-adjunct distinction. Semantically 'peripheral' elements such as location and beneficiary do not appear to be syntactically 'less core' than agent and patient. Both the 'peripheral' location and the 'core' patient, for instance, can be selected as the TOPIC, therefore triggering focus marking and being accessible to various syntactic processes. ${ }^{2}$ That is, the 'peripheral' location, conventionally identified as adjunct in most syntactic theories, does not appear to undergo further derivational processes for being associated with core syntactic position. It is thus doubtful how the conventional argument-adjunct distinction-

\footnotetext{
${ }^{2}$ Any semantic role selected for the TOPIC status is accessible to raising, relativization, control, and certain types of conjunction reduction.
} 


\section{Tsou SVCs and Argument Unification}

that agent and patient are arguments whereas all the other semantic roles are adjuncts - can be substantially obtained in Tsou.

While we claim that the conventional argument-adjunct distinction may not hold judging from the morphosyntax of Tsou, it would be an exaggeration to say that there is no argument-adjunct distinction in this language. Let us take locational nominals as example. While the common understanding assumes that all locational nominals are treated the same, Tsou in fact distinguishes two types of locational nominals: the one that can be selected for the TOPIC and trigger focus marking, as in (9), and the one that remains invariably NON-TOPIC and irrelevant to focus marking (in simplex predicates), as shown in (10)-(12).

$$
\begin{aligned}
& \text { i=si si-i to pooyoyo to amo 'o ca'hU } \\
& \text { AUX.NAF.R=3SG put-LF NTOP pants NTOP father TOP chair } \\
& \text { 'Father put pants on the chair.' (location=TOP, LF verb, NAF aux) } \\
& \text { *i=si chu-i to moatU'nU to amo 'o coca } \\
& \text { AUX.NAF.R=3SG butcher-LF NTOP goat NTOP father TOP yard } \\
& \text { intended: 'Father butchered a goat in the yard.' }
\end{aligned}
$$

$$
\begin{array}{llllll}
\mathrm{i}=\mathrm{si} & \text { chu-a } & \text { ne } & \text { coca to amo 'o moatU'nU } \\
\text { AUX.NAF.R=3SG butcher-PF } & \text { NTOP } & \text { yard NTOP father TOP } & \text { goat }
\end{array}
$$

'Father butchered the goat in the yard.' (location=NON-TOP)

$$
\begin{array}{llllll}
\mathrm{mo}=\varnothing & \mathrm{c}<\mathrm{m}>\text { uhu } & \text { ne } & \text { coca to moatU'nU 'o amo } \\
\text { AUX.AF.R =3SG } & <\mathrm{AF}>\text { butcher } & \text { NTOP } & \text { yard NTOP goat } & \text { TOP father }
\end{array}
$$

'Father butchered a goat in the yard.' (location= NON-TOP)

The above 'atypical' distinction should not be a big surprise if the argument-adjunct distinction is taken as a language-specific issue. To provide a descriptively appropriate characterization for the argument-adjunct dinstinction for the reset of the present study, I adopt the following Tsou-specific definition for argumenthood in this language: A nominal is taken to be of argument status when it can be selected for the TOPIC and therefore be accessible to various syntactic processes. This definition will be adopted as the criterion to examine whether or not a semantic element is included in the argument structure of the entire serial complex.

\section{Morphosyntax of Tsou SVCs}

\subsection{Verb Types in Tsou SVCs}

Three types of SVCs are considered in the present study. They come in the format of a restricted V1 slot followed by a comparatively unrestrictedly V2 slot. The three verbs that may occur in the V1 slot are the RF verb tith-eni 'use', the LF verb yon- $i$ 'stay', and the PF verb haf-a 'take', as shown in the examples in 


\section{Gujing Lin}

(13)-(15). Verb sequences such as 'go' plus 'see', while semantically felicitous in many languages, are not considered grammatical in Tsou, as shown in (16).

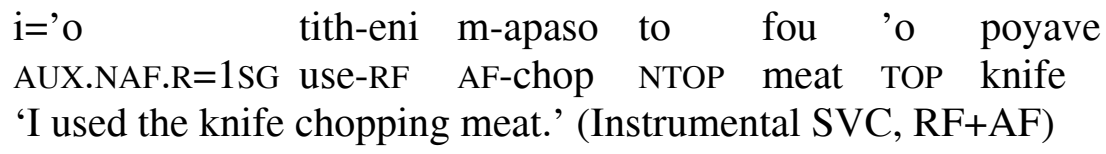

$$
\begin{array}{llllll}
\text { i='o } & \text { yon-i } & \text { m-apaso } & \text { to } & \text { fou 'o } & \text { oyonapei'i } \\
\text { AUX.NAF.R=1SG use-LF } & \text { AF-chop } & \text { NTOP } & \text { meat } & \text { TOP } & \text { kitchen } \\
\text { 'I stayed in the kitchen chopping meat.' (Locational SVC, LF+AF) }
\end{array}
$$

$$
\begin{aligned}
& \text { i='o haf-a uh to taipahu 'o naau } \\
& \text { AUX.NAF.R=1SG take-PF AF.go NTOP Taipei TOP Naau } \\
& \text { 'I took Naau to Taipei.' (Directional SVC, PF+AF) }
\end{aligned}
$$

$$
\begin{array}{llllll}
\text { *i=’o }_{\mathrm{i}} \text { us-a } & \text { b-aito } & \text { to } & \text { naau } & \text { 'o } & \text { taipahu } \\
\text { AUX.NAF.R=1SG go-PF } & \text { AF-see } & \text { NTOP } & \text { Naau } & \text { TOP } & \text { Taipei } \\
\text { intended: 'I went to Taipei to see Naau.' } &
\end{array}
$$

\subsection{Tsou SVCs and Syntactic Autonomy}

At first glance, the individual verbs in the above verb sequences appear to display features of syntactic autonomy, the most conspicous one being the different focus forms in which these verbs occur. Depending on verb types, the first verb may occur in one of the NAF forms; but the second verb is invariably in the AF form. These focus forms are all legitimate for making a grammatical sentence when used alone, as shown in Section 2. The fact that serialized verbs take different focus marking appears to suggest that individual verbs in the verb sequence still retain its syntactic independence and that the nature of Tsou SVCs is a combination of two syntactically autonomous verbs.

However, if we look carefully into the pattern of focus marking, the conflict in focus marking in fact demonstrates features of syntactic dependency. First, serialized verbs in Tsou come under strict syntactic constraints. Unlike simplex predicates which can alternate between AF and NAF forms under appropriate pragmatic context (depending on which semantic role is selected for the TOPIC), the first verb in SVCs is restricted to one of the NAF forms and the second verb is resricted to AF forms. Any change to focus forms is strictly prohibited. The examples (17) and (18) demonstrate that the verbs 'use' and 'chop' can alternate between AF and NAF forms when used alone in a monoclausal structure. When the two verbs occur in the serial verb context, however, they are bound by the focus constraint illustrated above, as shown in (19), (20), and (21).

$$
\begin{aligned}
& \text { mi='o titho } \quad \text { to } \quad \text { poyave } \\
& \text { AUX.NAF.R=1SG use.AF }
\end{aligned}
$$




\section{Tsou SVCs and Argument Unification}

i='o tith-eni 'o poyave ho papas-a 'o fou AUX.NAF.R=1SG use-RF TOP knife and chop-PF TOP meat 'I use the knife and chopped the meat.'

i='o tith-eni m-apaso to fou 'o poyave AUX.NAF.R=1SG use-RF AF-chop NTOP meat TOP knife 'I used the knife chopping meat yesterday.' (RF+AF)

$\begin{array}{lllll}* \text { mi='o } & \text { titho } & \text { m-apaso to fou to poyave }\end{array}$ intended: 'I used a knife chopping meat.' (AF+AF)

* $\mathrm{i}=$ 'o
tith-eni

The constraint on focus marking is accompanied with restricted finiteness. It was mentioned in Section 2 that a simplex finite verb controls the focus marking of the co-occurring auxiliary. An AF verb takes an AF auxiliary whereas a NAF verb requires a NAF auxiliary. In SVCs, the auxiliary is always marked in NAF, maintaining agreement with the first but not the second verb. This focus agreement indicates that serial verbs in Tsou are not equally autonomous; while the first verb displays finiteness features of an autonous verb, the second verb is restricted in finite marking and exhibits features of dependence. The syntactic dependence of the second verb also challenges Aikhenvald's claim that serial verbs do not illustrate any syntactic dependency, instead confirming Shibatani's and Crowley's arguments that serial verbs are not composed wholly of autonomous verbs.

\section{Tsou SVCs and Argument Unification}

If serial verbs are not equally syntactic autonomous, a question then emerges as to whether the individual verbs are equally important in contributing arguments to the serial complex. In the literature, an SVC is often characerized as a sequence of verbs acting together as a single predicate, which is then implicative of a single unified argument structure. Each of the serialized verbs is assumed to contribute arguments to the entire verb complex. For instance, Durie (1997) gives us an example from White Hmong where arguments contributed by individual verbs are fully fused into an integrated structure. When used alone, the White Hmong verbs muab 'take' and nqiaj 'cut' both take an agent and a patient in their respective argument structure. In serial context, the two verbs share the same agent and their patients are both incorporated into the joint structure, despite some modification: the patient of 'cut' is still the patient whereas the patient of 'take' is assigned the instrument role in the argument structure of the entire verb complex (Durie 1997:345-348). 


\section{Gujing Lin}

(22) Argument Unification in White Hmong (based on Durie 1997: 345-347)

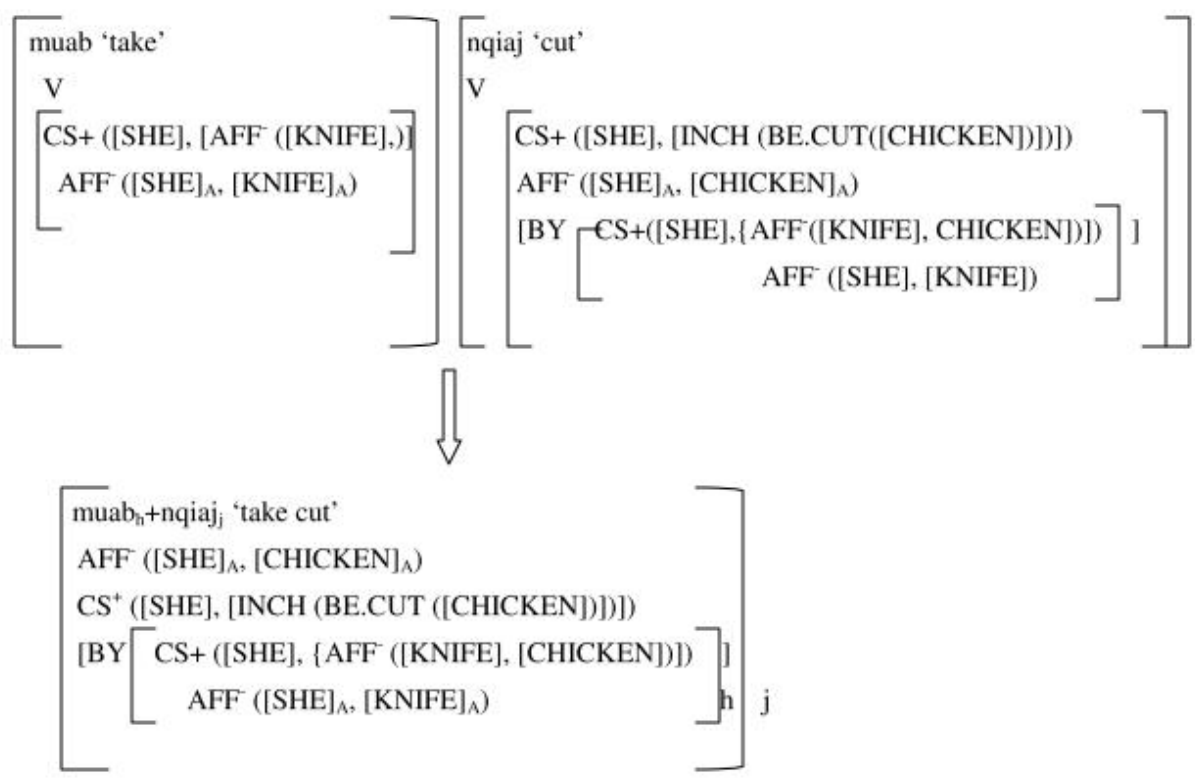

Now, let us look at how individual verbs contribute arguments in the Tsou SVCs. In Section 2 we proposed to define a Tsou argument as a nominal that can be selected for the TOPIC and trigger focus marking on the verb. When used alone, the verb 'stay' involves two event participants: an actor and a location. Both participants can be selected as the TOPIC and trigger the appropriate focus marking on the verb, as shown in (23) and (24) below. By our definition, the verb takes a two-argument frame. A similar two-argument frame is observed in the verb 'chop', which involves an agent acting on a patient and both participants can be selected for the TOPIC, as shown in (25) and (26).

$$
\mathrm{mo}=\varnothing \quad \text { yon to oyonapei'i 'o oko=si }
$$

AUX.AF.R $=3$ SG stay.AF NTOP kitchen TOP child=3SG

'His child stayed in a/the kitchen.' (simple predicate, agent=TOP)

$$
\mathrm{i}=\mathrm{si} \quad \mathrm{yon}-\mathrm{i} \text { to } \mathrm{oko}=\mathrm{si} \text { 'o oyonapei'i }
$$

AUX.NAF.R $=3 \mathrm{SG}$ stay-LF NTOP child=3SG TOP kitchen

'His child stayed in the kitchen.' (simple predicate, location=TOP)

$$
\begin{array}{llllll}
\text { mo }=\varnothing & \text { m-apaso } & \text { to } & \text { fou } & \text { 'o } & \text { oko }=s i \\
\text { AUX.AF.R=3SG } & \text { AF-chop } & \text { NTOP } & \text { meat } & \text { TOP } & \text { child=3SG }
\end{array}
$$

'His child chopped meat.' (simple predicate, agent=TOP)

$\mathrm{i}=\mathrm{si}$ papas-a to $\mathrm{oko}=\mathrm{si}$ 'o fou

AUX.NAF.R=3SG chop-PF NTOP child=3SG TOP meat

'His child chopped the meat.' (simplex predicate, patient=TOP) 


\section{Tsou SVCs and Argument Unification}

When the verb 'stay' occurs in the serial verb context together with 'chop', however, only the location nominal (contributed by 'stay') is allowed to be selected as the TOPIC and trigger the LF marking. The patient nominal (by 'chop') remains invariably as the NON-TOPIC and never gets to trigger focus marking in the verb sequence. Such restriction suggests that the patient nominal contributed by the second verb 'chop' does not acquire argument status in the serial complex. Instead, it displays features of an adjunct (see the examples (9)-(12)).

$\begin{array}{llll}\text { i=si } & \text { yon-i } & \text { m-apaso to } & \text { fou } \\ \text { AUX.NAF.R=3SG } & \text { stay-LF } & \text { AF-chop NTOP } & \text { meat } \\ \text { to } \quad \text { oko=si } & \text { 'o } & \text { oyonapei'i } & \\ \text { NTOP } & \text { child=3SG } & \text { TOP } & \text { kitchen }\end{array}$

'His child stayed in the kitchen chopping meat.' (SVC, location=TOP)

$$
\begin{aligned}
& * \mathrm{i}=\mathrm{si} \quad \text { yon- } \mathrm{i} \text { papas-a to oyonapei' } \mathrm{i} \\
& \text { AUX.AF.R=3SG stay-LF chop-PF NTOP kitchen } \\
& \text { to oko=si 'o fou } \\
& \text { NTOP child }=3 \mathrm{SG} \text { TOP meat } \\
& \text { intended: 'His child stayed in a kitchen chopping the meat.' } \\
& (\mathrm{SVC} \text {, patient=TOP) }
\end{aligned}
$$

The above constraint illustrates that the serial complex does not subcategorize all the arguments contributed by each of its component verbs. The argument structures of individual verbs are not (fully) unified into an integrated set. Judging by the pattern of TOPIC marking, only the non-actor argument of the first verb can be convincingly shown to acquire the argument status in the serial complex. The arguments contributed by the second verb, given the restriction on nominal marking, are not incorporated into the argument structure of the entire verb complex.

\section{Conclusion}

The present study considers three Tsou SVCs and discusses their features of syntactic autonomy and pattern of argument unification. In the three constructions, although the individual verbs each show formal resemblance to independent finite verbs, only the first verb displays the full-fledged features of an independent, finite verb. The second verb is highly restricted in finite marking, illustrating features of syntactic dependency.

The difference in syntactic autonomy is correlated with the pattern of argument assignment between each of the component verbs in the serial verb context. Judging by the pattern of TOPIC marking, only the non-actor argument of the first verb is included in the argument structure of the entire serial complex; the arguments contributed by the second verb are never selected as the TOPIC in SVCs 


\section{Gujing Lin}

and are arguably not an argument of the verb complex. Given the morphosyntactic features considered in the present study, arguments of individual verbs are not unified into an integrated set in the three SVCs of Tsou.

\section{References}

Aikhenvald, Alexandra Y. 2006. Serial verb constructions in typological perspective. In Alexandra Y. Aikhenvald and R.M.W. Dixon, eds., Serial verb constructions: A cross linguistic typology, 1-68. New York: Oxford UP.

Bisang, Walter. 1995. Verb serialization and converbs--differences and similarities. In Martin Haspelmath and Ekkehard König, eds., Converbs in cross-linguistic perspective: Structure and meaning of adverbial verb forms, 137-88. Berlin: Mouton de Gruyter.

Bril, Isabelle. 2004. Complex predicates in Oceanic languages: Contribution to an areal typology. In Isabelle Bril and Françoise Ozanne-Rivierre, eds., Complex predicates in Oceanic languages: Studies in the dynamics of binding and boundness, 1-48. Empirical approaches to language typology 29. New York: Mouton de Gruyter.

Crowley, Terry. 2002. Serial verbs in oceanic: A descriptive typology. Oxford and New York: Oxford UP.

Durie, Mark. 1997. Grammatical structures in verb serialization. In A. Alsina, J. Bresnan, and P. Sells, eds., Complex predicates, 289-354. Stanford: CSLI.

Foley, William A., and Mike Olson. 1985. Clausehood and verb serialization. In J. Nichols and A. C Woodbury, eds., Grammar inside and outside the clause: Some approaches to theory from the field, 17-60. Cambridge: Cambridge UP.

Shibatani, Masayoshi. 2007. On the form of complex predicates. Ms., Rice University.

Gujing Lin

Rice University

Department of Linguistics

6100 Main Street

Houston, TX 77005

serene@rice.edu 